EPSC Abstracts

Vol. 15, EPSC2021-534, 2021

https://doi.org/10.5194/epsc2021-534

Europlanet Science Congress 2021

(C) Author(s) 2022. This work is distributed under

the Creative Commons Attribution 4.0 License.

\title{
Observing rocks in Jezero crater, Mars: results of the first months of operation of the SuperCam VISIR spectrometer
}

Lucia Mandon ${ }^{1}$, Cathy Quantin-Nataf ${ }^{2}$, Pierre Beck ${ }^{3}$, Thierry Fouchet ${ }^{1}$, Clément Royer $^{1}$, Franck Montmessin ${ }^{4}$, Olivier Forni ${ }^{5}$, Jeffrey R. Johnson ${ }^{6}$, Olivier Gasnault ${ }^{5}$, Erwin Dehouck ${ }^{2}$, François Poulet ${ }^{7}$, Adrian Brown ${ }^{8}$, Jesse D. Tarnas ${ }^{9}$, Stéphane Le Mouélic ${ }^{10}$, Pernelle Bernardi ${ }^{1}$, Jean-Michel Reess ${ }^{1}$, Raymond T. Newell ${ }^{11}$, Sylvestre Maurice ${ }^{5}$, and Roger C. Wiens ${ }^{11}$

${ }^{1}$ LESIA, Observatoire de Paris, Université PSL, CNRS, Sorbonne Université, Université de Paris, Meudon, France

(lucia.mandon@obspm.fr)

${ }^{2}$ Université de Lyon, UCBL, ENSL, CNRS, LGL-TPE, Lyon, France

${ }^{3}$ Université Grenoble-Alpes, CNRS, IPAG, UMR 5274, Grenoble, France

${ }^{4}$ LATMOS, CNRS, Univ. Saint-Quentin-en-Yvelines, Sorbonne Univ., Guyancourt, France

${ }^{5}$ IRAP, CNRS, Université de Toulouse, UPS-OMP, Toulouse, France

${ }^{6}$ Johns Hopkins University Applied Physics Laboratory, Laurel, Maryland, USA

${ }^{7}$ Institut d'Astrophysique Spatiale, CNRS/Paris-Sud University, France

${ }^{8}$ Plancius Research, MD, USA

${ }^{9}$ NASA, JPL, Caltech, USA

${ }^{10}$ LPG Nantes, UMR 6112, CNRS, OSUNA, Université de Nantes, Nantes, France

${ }^{11}$ Los Alamos National Laboratory, Los Alamos, NM, USA

The Perseverance rover (Mars 2020 mission, NASA) landed in the ancient lakebed of Jezero crater, Mars on February $18^{\text {th }}, 2021$. The main science objectives of the mission are the characterization of past habitable environments, the search for preserved biosignatures and the collection of samples to be returned to Earth by the next MSR (Mars Sample Return, NASA/ESA) mission [1]. The payload includes the SuperCam instrument (under the leadership of LANL, USA and IRAP, France), which plays a critical role in the exploration strategy, as it combines various remote-sensing techniques to investigate the elemental and mineralogical composition of rocks and soils: high-resolution color imaging, laser-induced breakdown spectroscopy, Raman spectroscopy, visible and near-infrared (VISIR) reflectance spectroscopy, and acoustic sensing [2, 3, 4, 5]. In particular, the near-infrared spectrometer is a novel instrument on the Martian surface. The spectra, together with data from two additional visible spectrometers, cover 0.39-0.85 $\mu \mathrm{m}$ (VIS) and 1.3-2.6 $\mu \mathrm{m}$ (IR), which allows the identification of a wide variety of minerals. 


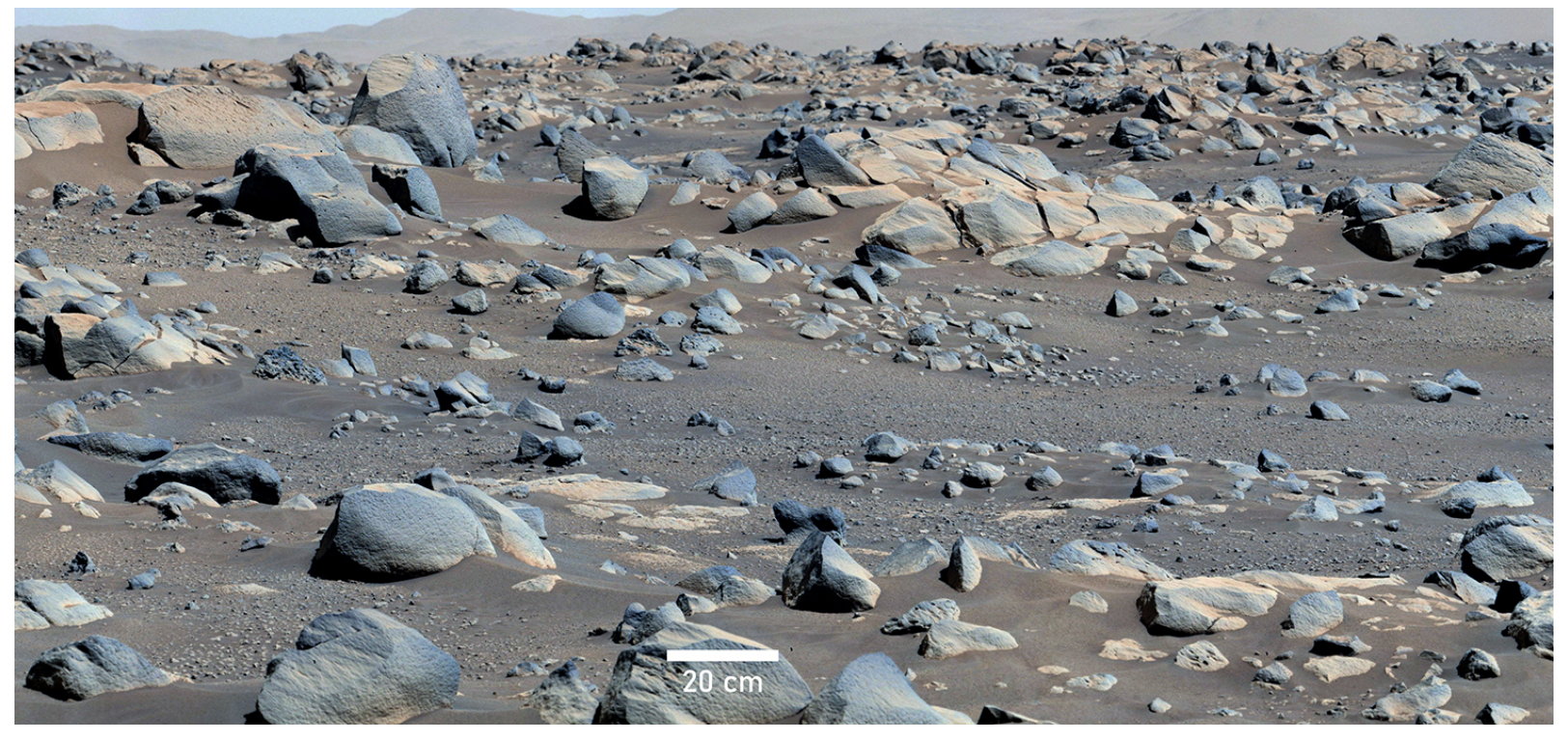

Figure 1. Enhanced-color mosaic of images taken by the Mastcam-Z Left camera of the rover workspace on sol 78 [6]. NASA/Caltech-JPL/MSSS/ASU.

Orbital data show that the landing site exhibits diverse mineralogical assemblages in various geological contexts, attesting in particular of an ancient aqueous activity during the Noachian and Hesperian eras (> $3 \mathrm{Ga}$ ), and including mafic minerals, carbonates, phyllosilicates and opaline silica $[7,8,9]$.

We present the initial results of the SuperCam VISIR spectrometers, with calibrated [10] spectral data collected in the first months of operation of the instrument, with a focus on the rocks and soils present in the rover workspace and explored so far. Spectra have been obtained on nearby rocks so far within $50 \mathrm{~m}$ of the Octavia E. Butler landing site, at the boundaries of the Crater Floor Fractured Rough (CF-Fr) and Crater Floor Fractured (CF-F) units, which from orbit exhibit the spectral signatures of pyroxene and olivine, respectively [7]. A comparison with orbital data is presented in [11].

Most of the rocks analyzed in the close vicinity of the rover so far consists of light-toned 'pavers' and upstanding dark-toned rocks (Fig. 1). Some variability in reflectance levels and absorption bands is observed within and between the rocks (Fig. 2), but overall they share similar spectral characteristics in the VISIR. In particular, they all exhibit an absorption band near $1.9 \mu \mathrm{m}$ (a spectral signature indicating the presence of the water molecule), a band that is usually not observed in the soils - at least not with the same depth. This absorption near $1.9 \mu \mathrm{m}$ is also present in spectral observations of outcrops a few kilometers away from the rover [11]. In addition to this absorption at $\sim 1.9 \mu \mathrm{m}$, a blue slope in the 2.1-2.5 $\mu \mathrm{m}$ region and subtle absorption bands near 1.4 $\mu \mathrm{m}$ and $2.28 \mu \mathrm{m}$ show up locally, which suggests the presence of hydrated mineral species, such as an iron-rich phyllosilicate (like nontronite or hisingerite), potentially mixed with an oxy-hydroxide such as ferrihydrite (Fig. 2). The intensity of these absorption bands is consistent with at least a few weight percent of these hydrated species in the observed target, either in the bulk of the rock or in a varnish/coating. Finally, fewer spectra exhibit a weak absorption at $2.2 \mu \mathrm{m}$, suggesting the additional presence of an $\mathrm{Al}-\mathrm{OH}$ or $\mathrm{Si}-\mathrm{OH}$-bearing phase.

Overall, the detection of these widespread hydration features supports some pervasive water-rock interactions during the past, in the landing site of Perseverance. CRISM data suggest that we have landed in a relatively low hydration region, and that the rover will be driving through progressively increasing hydration throughout the mission, as it moves onto the delta, the olivine-carbonate and the region outside of Jezero crater. Future in situ measurements on these potentially more hydrated 
and diverse rocks are expected to bring new insights into the past aqueous environment at Jezero crater.
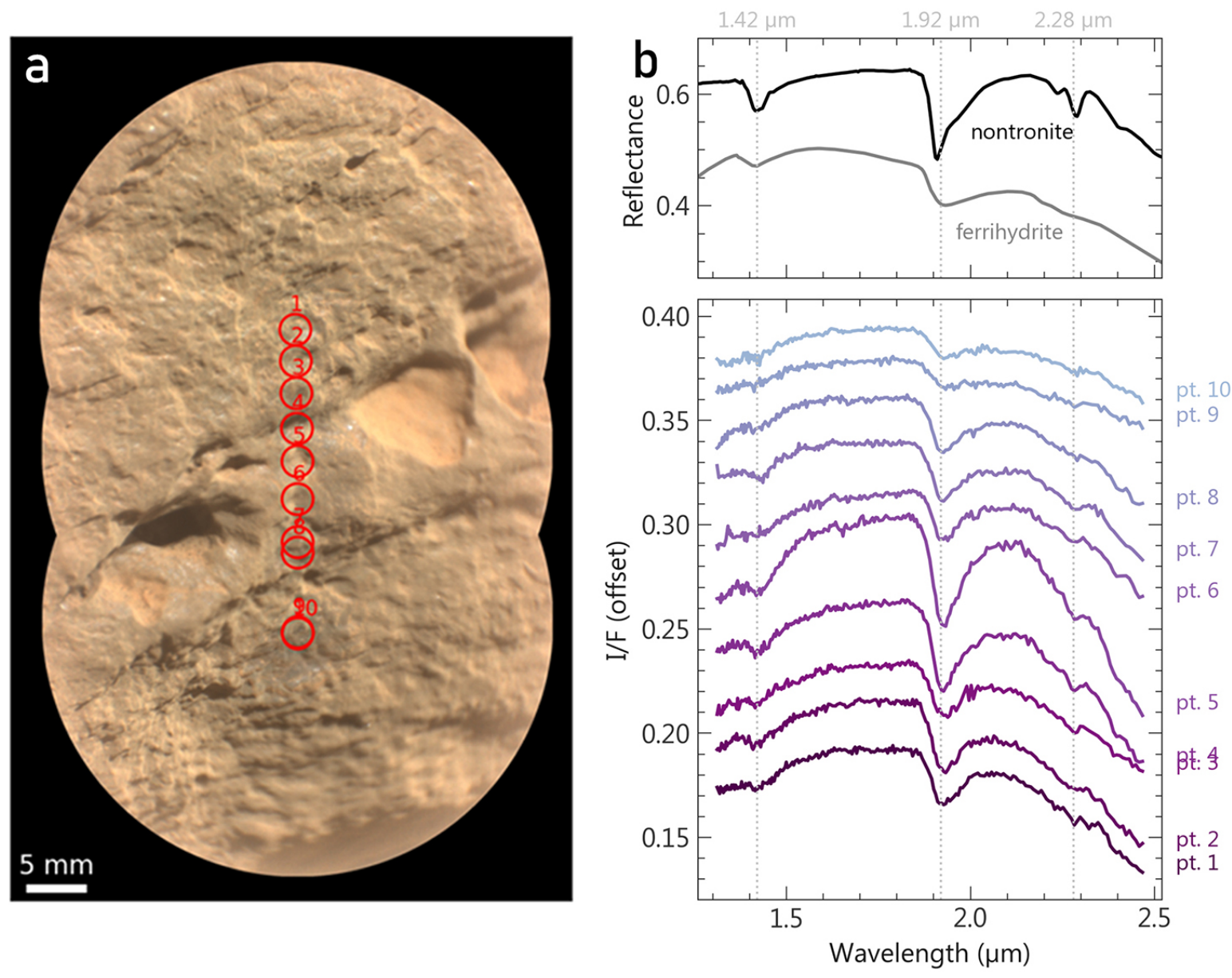

Figure 2. Example of a SuperCam observation on a rock present in the workspace of the rover: 10x1 raster on target Bidziil. (a) RMI mosaic taken at $2.3 \mathrm{~m}$ from the rover mast on sol 56 with the IRS $68 \%$ field of view annotated in red. (b) Corresponding IRS spectra in color, compared to laboratory spectra of known minerals in black and grey.

\section{References}

[1] Farley, K. A. et al., 2020. Space Sci. Rev.; [2] Wiens, R.C. et al., 2017. Spectroscopy; [3] Maurice, S. et al., 2021 Space Sci. Rev.; [4] Cousin, A. et al., this conference; [5] Chide, B. et al., this conference; [6] Bell, J. F. et al., 2021. Space Sci. Rev. [7] Goudge, T. A. et al., 2015. J. Geophys. Res. Planets; [8] EhImann, B. L. et al., 2008. Science; [9] Tarnas, J. D. et al., 2019. Geophys. Res. Lett.; [10] Royer, C. et al., this conference; [11] Quantin-Nataf et al., this conference. 